2 Atomically Dispersed Manganese on a Carbon-Based Material for the Capture of Gaseous

3 Mercury: Mechanisms and Environmental Applications

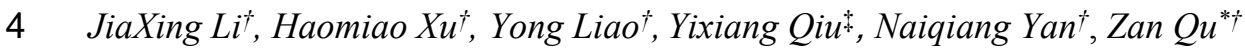

$5 \uparrow$ School of Environmental Science and Engineering, Shanghai Jiao Tong University, 800

6 Dongchuan Road, Shanghai 200240, China

$7 \ddagger$ School of Chemistry and Chemical Engineering, Shanghai Jiao Tong University, 800 Dongchuan

8 Road, Shanghai 200240, China

$9 \quad *$. Corresponding author, telephone: 86-021-54745591; E-mail: quzan@sjtu.edu.cn

12 Number of pages:13

13 Number of figures:9

14 Number of tables:0

15

16 
$6 \mathrm{~g} \mathrm{MnCl}_{2} \cdot 4\left(\mathrm{H}_{2} \mathrm{O}\right)$ and $1.5 \mathrm{~g} \mathrm{ZnCl}_{2}$ were dissolved into $200 \mathrm{~mL}$ deionized water. Then, $6 \mathrm{~g}$ chitosan was dispersed into the above solution under stirring at $85^{\circ} \mathrm{C}$ until the water evaporated completely. Subsequently, the solid mixture was heated at $900{ }^{\circ} \mathrm{C}$ for $1 \mathrm{~h}$ under $\mathrm{N}_{2}$ with a heating rate of $5^{\circ} \mathrm{C} \cdot \mathrm{min}^{-}$ 1. The derived carbon material was transferred into $2 \mathrm{M} \mathrm{HCl}$ solution and rotary evaporation at 120 ${ }^{\circ} \mathrm{C}$ for $8 \mathrm{~h}$ to remove soluble salts and generated manganese nanoparticles. Finally, the product was filtered and washed several times by deionized water and anhydrous ethanol and dried in oven at 60 ${ }^{\circ} \mathrm{C}$.

\section{Synthesis of Chitosan-C}

$6 \mathrm{~g}$ chitosan and $1.5 \mathrm{~g} \mathrm{ZnCl}_{2}$ were dissolved into $200 \mathrm{~mL}$ deionized water directly under stirring at $85^{\circ} \mathrm{C}$ until the water evaporated completely. Then, the washed solid mixture was heated at $900^{\circ} \mathrm{C}$ for $1 \mathrm{~h}$ under $\mathrm{N}_{2}$ with a heating rate of $5^{\circ} \mathrm{C} \cdot \mathrm{min}^{-1}$

. The derived carbon material was transferred into $2 \mathrm{M} \mathrm{HCl}$ solution and rotary evaporation at $120^{\circ} \mathrm{C}$ for $8 \mathrm{~h}$. Finally, the product was filtered and washed several times by deionized water and anhydrous ethanol and dried in oven at $60^{\circ} \mathrm{C}$.

\section{Synthesis of MnOx@Chitosan-C}

To obtain samples of 1\%MnOx@Chitosan-C,1g Chitosan-C was dispersed into 100 mL deionized water under stirring. Then, $45.688 \mathrm{mg} \mathrm{Mn}\left(\mathrm{NO}_{3}\right)_{2} \cdot 4 \mathrm{H}_{2} \mathrm{O}$ was added into the above mixture solution for $1 \mathrm{~h}$ stirring. The resulting solution was transferred into the rotary evaporation at $75{ }^{\circ} \mathrm{C}$ until the water evaporated. Subsequently, the solid mixture was heated at $500{ }^{\circ} \mathrm{C}$ for $2 \mathrm{~h}$ under $\mathrm{N}_{2}$ with a heating rate of $5^{\circ} \mathrm{C} \cdot \mathrm{min}^{-1}$. The obtained carbon material was directly used without further treatment. The 5\%MnOx@Chitosan-C and 10\%MnOx@Chitosan-C sample were prepared by the same procedure except different $\mathrm{Mn}\left(\mathrm{NO}_{3}\right)_{2} \cdot 4 \mathrm{H}_{2} \mathrm{O}$ mass. $6 \mathrm{~g} \mathrm{MnCl}_{2} \cdot 4\left(\mathrm{H}_{2} \mathrm{O}\right)$ and $1.5 \mathrm{~g} \mathrm{ZnCl}_{2}$ were dissolved into $200 \mathrm{ml}$ deionized water. Then, $6 \mathrm{~g}$ melamine was dispersed into the above solution under stirring at $85^{\circ} \mathrm{C}$ until the water evaporated completely. Subsequently, the solid mixture was heated at $900^{\circ} \mathrm{C}$ for $1 \mathrm{~h}$ under $\mathrm{N}_{2}$ with a heating rate of $5^{\circ} \mathrm{C} \cdot \mathrm{min}^{-}$

44 . The derived carbon material was transferred into $2 \mathrm{M} \mathrm{HCl}$ solution and rotary evaporation at 120 
${ }^{\circ} \mathrm{C}$ for $8 \mathrm{~h}$ to remove soluble salts and generated manganese nanoparticles. Finally, the product was filtered and washed several times by deionized water and anhydrous ethanol and dried in oven at 60 ${ }^{\circ} \mathrm{C}$.

\section{Computational methods}

Geometry optimizations and frequency calculations of Mn-N4, Mn-O1N3, Mn-O2N2-p, MnO2N2o, Mn-O3-N1 and Mn-O4 were performed with the hybrid M06-2X exchange-correlation functional ${ }^{[1]}$.This functional was chosen because its reliable performance in describing the single metal atoms system The Stuttgar ${ }^{[2]}$ energy consistent quasirelativistic small-core pseudopotentials were used to account for the scalar relativistic effects and to reduce the computational cost for $\mathrm{Mn}$ and $\mathrm{Hg}$ atoms, and the $6-311 \mathrm{G}(\mathrm{d})$ basis set for all the other atoms. All calculations were implemented in the Gaussian03 program ${ }^{[3]}$.

\section{Mn atom utilization efficiency calculation methods}

The manganese atom utilization efficiency was calculated by applying the following formulae:

$$
\begin{aligned}
& n_{H g}=\frac{\mathrm{C} \cdot \mathrm{m}}{M_{H g}} \\
& n_{M n}=\frac{\mathrm{m} \cdot \mathrm{a}}{M_{M n}}
\end{aligned}
$$

$$
\text { atomic utilization efficiency }(\%)=\frac{n_{H g}}{n_{M n}} \times 100 \%
$$

where $\mathrm{C}$ represents the $\mathrm{Hg}^{0}$ adsorption capacity of sorbent, $\mathrm{m}$ represents the mass of sorbent, a represents the Mn load ration on sorbent, $\mathrm{n}_{\mathrm{Hg}}$ and $\mathrm{n}_{\mathrm{Mn}}$, respectively, represent the amount of substance of $\mathrm{Hg}$ and $\mathrm{Mn}, \mathrm{M}_{\mathrm{Hg}}$ and $\mathrm{M}_{\mathrm{Mn}}$ respectively represent the molar mass of $\mathrm{Hg}$ and $\mathrm{Mn}$. 


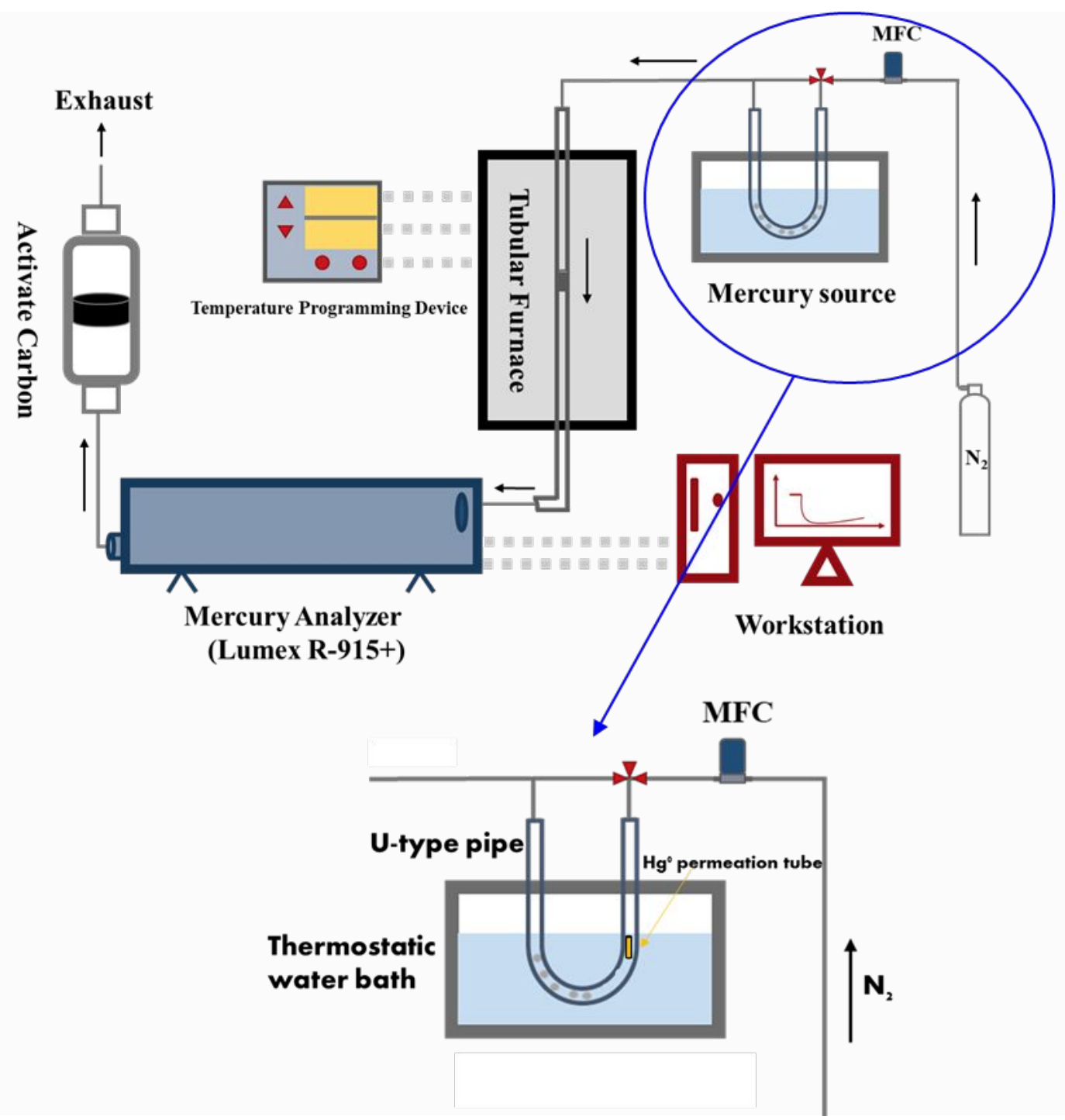

Figure S1. Schematic of the $\mathrm{Hg}^{\mathbf{0}}$ adsorption evaluation system. 


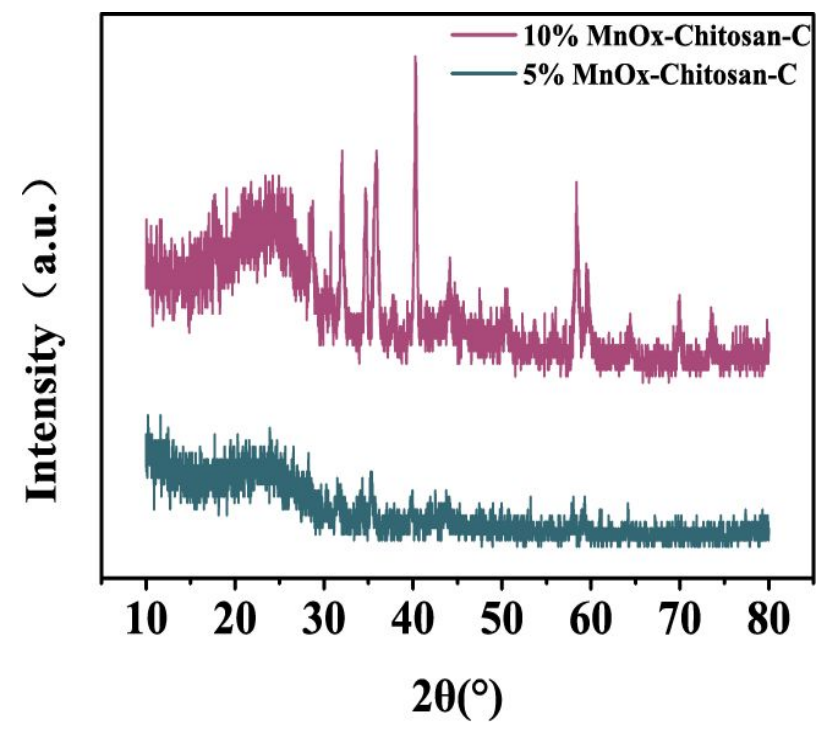

77

Figure S2. XRD patterns of $10 \% \mathrm{MnOx}-\mathrm{Chitosan}-\mathrm{C}, 5 \% \mathrm{MnOx}-\mathrm{Chitosan}-\mathrm{C}$.

78

79 

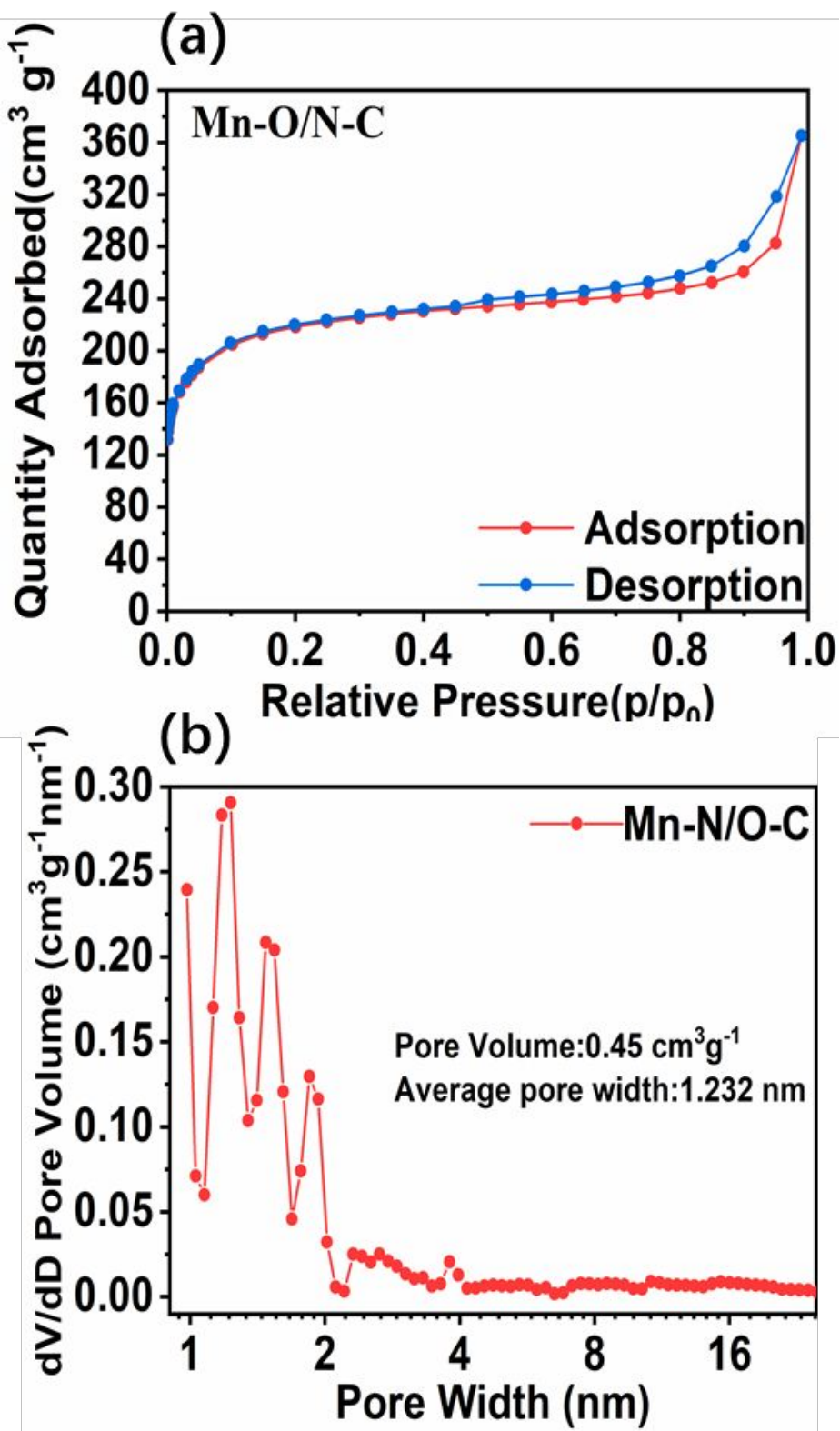

81 Figure S3 (a). $\mathbf{N}_{2}$ adsorption-desorption analysis and (b) pore size distribution of $\mathrm{Mn}-\mathrm{O} / \mathrm{N}-\mathrm{C}$.

82 
Figure S4. SEM image of Mn-O/N-C in size of $3 \mu \mathrm{m}$ and $500 \mathrm{~nm}$.

85 

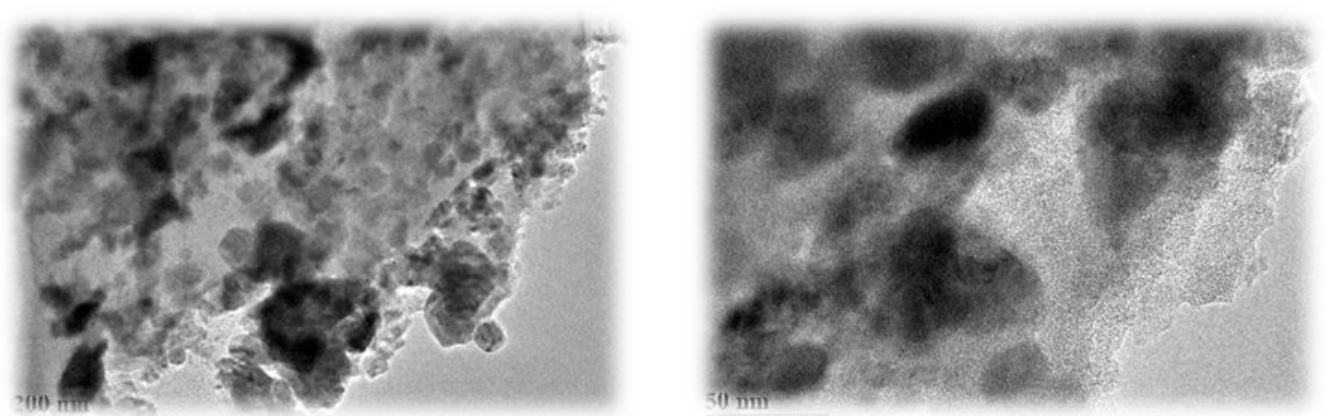

Figure S5. HRTEM image of $1 \%$ MnOx-Chiosan-C in size of $200 \mathrm{~nm}, 50 \mathrm{~nm}$ and $5 \mathrm{~nm}$.

88 


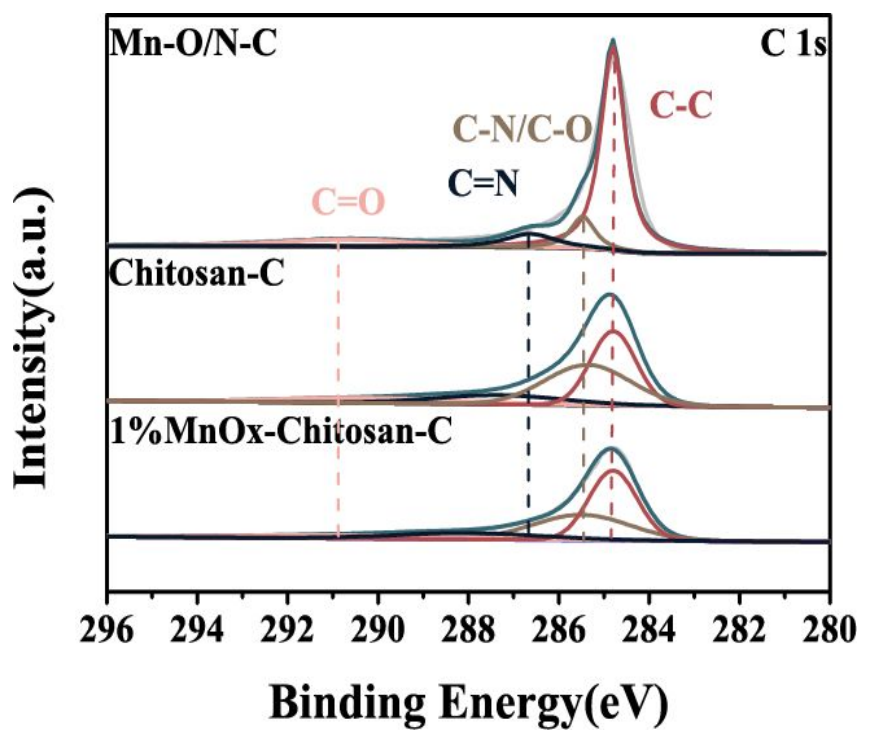

90

Figure S6. C1s XPS spectra of Mn-O/N-C,Chitosan-C,1\%Mn-Chitosan-C

91 


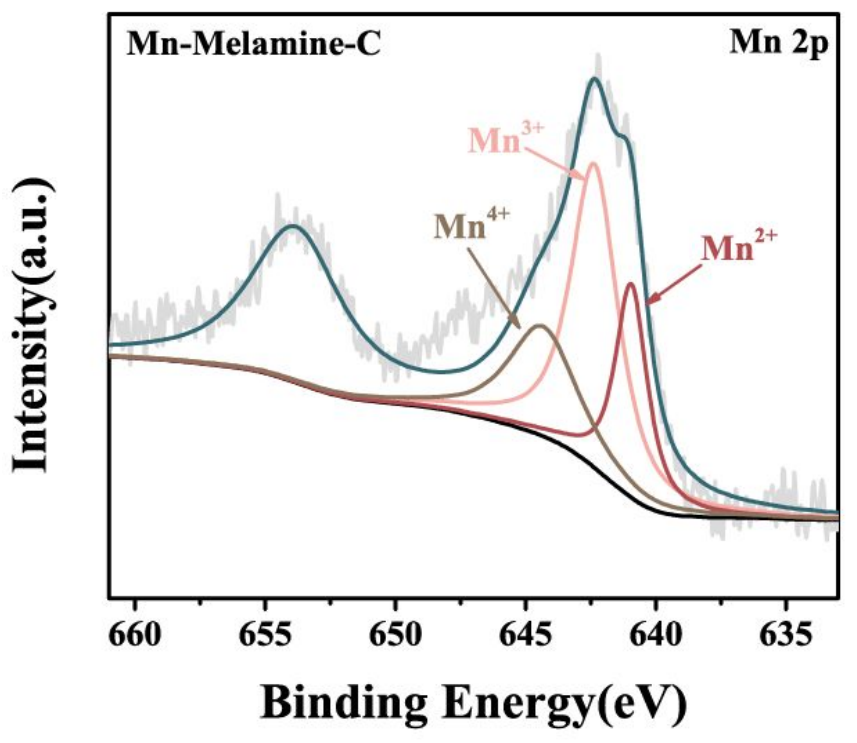

93

Figure S7. Mn2p XPS spectra of Mn-Melamine-C

94 


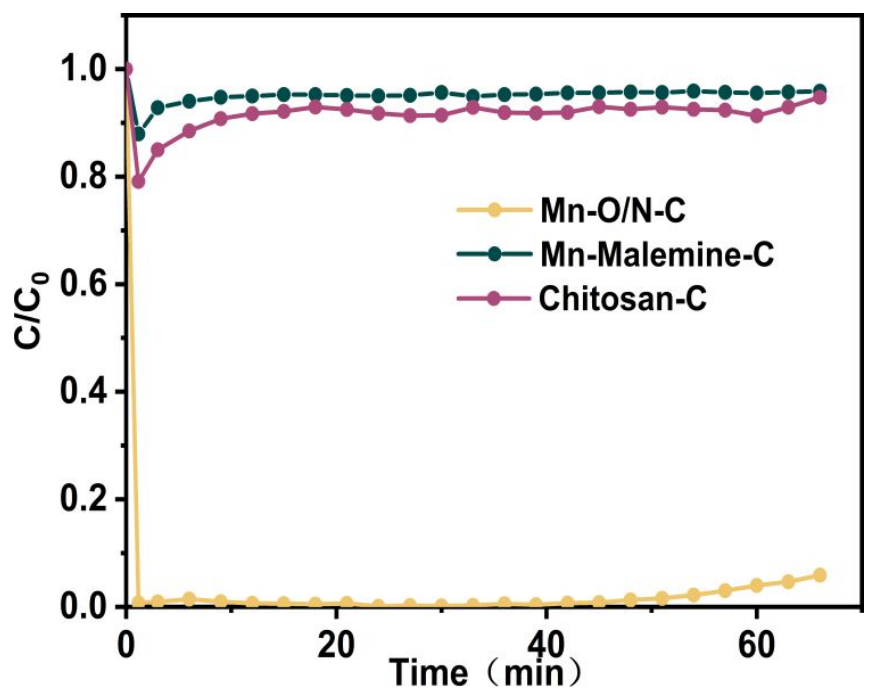

Figure S8. Hg ${ }^{0}$ adsorption breakthrough curves of Mn-O/N-C compared with Mn-

98 Reaction conditions: sorbent $\operatorname{mass}=\mathbf{1 0} \mathrm{mg}$, flow rate $=\mathbf{5 0 0} \mathrm{mL} \cdot \mathrm{min}^{-1}$, adsorption time $=$ 
101

102 103 104

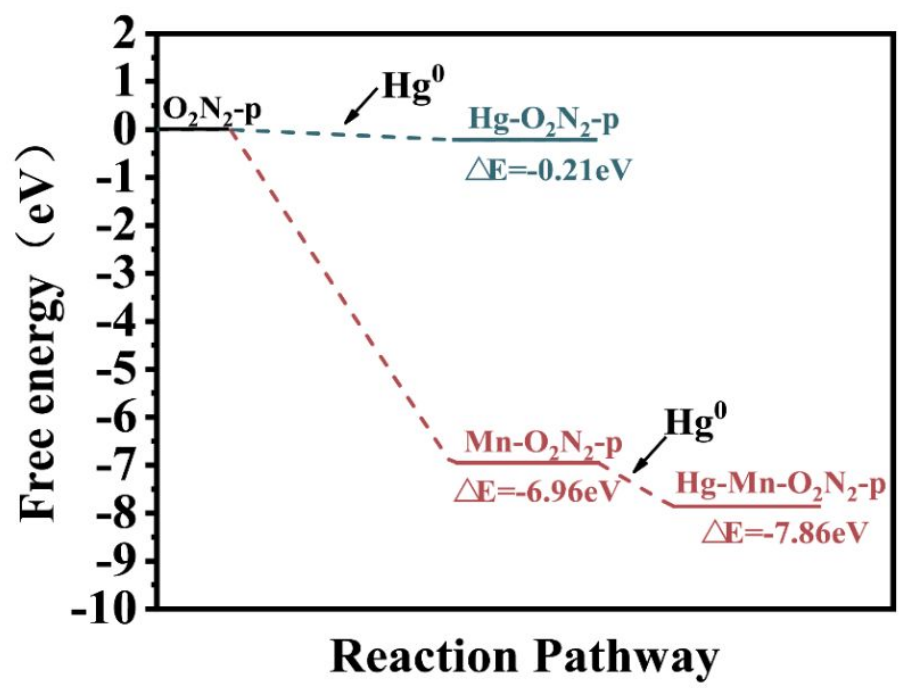

Figure S9. Energy profile of $\mathrm{O} 2 \mathrm{~N} 2-p$ structure in two $\mathrm{Hg}^{0}$ adsorption ways 
106 (1) (a) Zhao Y, Truhlar D G. A new local density functional for main-group thermochemistry, transition metal bonding, thermochemical kinetics, and noncovalent interactions. The Journal of chemical physics, 2006, 125(19): 194101. (b) Zhao Y, Truhlar D G. The M06 suite of density

109 functionals for main group thermochemistry, thermochemical kinetics, noncovalent interactions,

110 excited states, and transition elements: two new functionals and systematic testing of four M06-class

111 functionals and 12 other functionals. Theoretical Chemistry Accounts, 2008, 120(1-3): 215-241.

112 (2) Dolg M, Stoll H, Preuss H, et al. Relativistic and correlation effects for element 105 (hahnium, Ha):

113 a comparative study of $\mathrm{M}$ and $\mathrm{MO}(\mathrm{M}=\mathrm{Nb}, \mathrm{Ta}, \mathrm{Ha})$ using energy-adjusted ab initio pseudopotentials.

114 The Journal of Physical Chemistry, 1993, 97(22): 5852-5859.

115 (3) Frisch, M. J.; Trucks, G. W.; Schlegel, H. B.; et al. Gaussian 03, revision B.04; Gaussian, Inc:

116 Wallingford, CT, 2004. 